\title{
ARTICLE
}

Received 13 May 2013 | Accepted 18 Nov 2013 | Published 16 Dec 2013 DOl: 10.1038/ncomms3950

\section{All-back-contact ultra-thin silicon nanocone solar cells with $13.7 \%$ power conversion efficiency}

Sangmoo Jeong', Michael D. McGehee ${ }^{2} \& \mathrm{Yi} \mathrm{Cui}^{2,3}$

Thinner Si solar cells with higher efficiency can make a Si photovoltaic system a cost-effective energy solution, and nanostructuring has been suggested as a promising method to make thin $\mathrm{Si}$ an effective absorber. However, thin Si solar cells with nanostructures are not efficient because of severe Auger recombination and increased surface area, normally yielding $<50 \%$ EQE with short-wavelength light. Here we demonstrate $>80 \%$ EQEs at wavelengths from 400 to $800 \mathrm{~nm}$ in a sub-10- $\mu \mathrm{m}$-thick Si solar cell, resulting in $13.7 \%$ power conversion efficiency. This significant improvement was achieved with an all-back-contact design preventing Auger recombination and with a nanocone structure having less surface area than any other nanostructures for solar cells. The device design principles presented here balance the photonic and electronic effects together and are an important step to realizing highly efficient, thin Si and other types of thin solar cells.

\footnotetext{
${ }^{1}$ Department of Electrical Engineering, Stanford University, Stanford, California 94305, USA. ${ }^{2}$ Department of Materials Science and Engineering, Stanford University, Stanford, California 94305, USA. ${ }^{3}$ Stanford Institute for Materials and Energy Sciences, SLAC National Accelerator Laboratory, Menlo Park, California 94205, USA. Correspondence and requests for materials should be addressed to Y.C. (email: yicui@stanford.edu).
} 
$\mathrm{N}$ anostructured solar cells have recently been investigated intensively because of their promise for low-cost materials and processing ${ }^{1-6}$, effective anti-reflection and light trapping for materials saving ${ }^{7-9}$, light-weight and mechanical flexibility for low-cost installation ${ }^{10,11}$ and miniaturized energy sources ${ }^{12}$. However, these exciting concepts thus far give power conversion efficiency lower than their bulk counterparts. In particular, a silicon ( $\mathrm{Si}$ ) solar cell is still the mainstream technology in industry, and it has witnessed significant cost reduction in the past decade: its module cost was dropped from $\$ 33.44 / \mathrm{W}$ in 1980 to under $\$ 1 / \mathrm{W}$ in 2012 (ref. 13). In order to make a photovoltaic system cost-competitive without subsidies, its module cost should be $<\$ 0.5 / \mathrm{W}$ (ref. 14). Reducing a Si absorber thickness from 200 to sub- $10 \mu \mathrm{m}$ can potentially have a large impact on reducing the module cost further and enabling light-weight installation. The conventional surface texturing with alkaline or acidic solution for sub-10- $\mu \mathrm{m}$ thick Si substrates requires additional masking steps including photolithography ${ }^{15}$, and it is hard to implement on thin substrates with high yield ${ }^{16}$. In the past several years, significant effort has been focused on enhancing the light absorption by nanoscale light trapping using nanowires ${ }^{8,17-19}$, nanocones ${ }^{20-22}$, nanodomes ${ }^{f}$ and nanoholes ${ }^{23-26}$. Despite the exciting success in light trapping, the power conversion efficiencies of nanostructured Si solar cells, however, remain below 19\% for thick devices ${ }^{26}$ and below $11 \%$ for thin devices ${ }^{27}$.

Here, we present a sub-10- $\mu$ m-thick Si solar cell with a $13.7 \%$ power conversion efficiency that overcomes the critical problems of nanostructured devices: Auger and surface recombination. In general, nanostructured solar cells have a highly doped emitter layer at the front, fabricated by high-temperature diffusion processes. Because the diffusion profile of the dopants is dependent on the surface morphology, a nanostructured device tends to have a much deeper junction depth with a higher concentration compared with a planar device ${ }^{26,28}$. It leads to severe Auger and surface recombination of charge carriers ${ }^{29}$. Another problem of nanostructured Si solar cells is the increased surface area. For example, a porous nanostructure with $\sim 300 \mathrm{~nm}$ depth and $50 \mathrm{~nm}$ diameter has $800 \%$ more surface area than a planar structure. Considering the fact that the surface recombination becomes more critical to device performance as the absorber becomes thinner, the increased surface area in a thin Si solar cell can lead to a severe decrease of efficiency. In particular, the increased loss to Auger and surface recombination becomes worse for short-wavelength light, which is absorbed near the surface, normally yielding $<50 \%$ external quantum efficiency (EQE) at $400 \mathrm{~nm}$ wavelength light. Owing to these problems, thin $\mathrm{Si}$ solar cells with nanostructures are not as efficient as they could be.

\section{Results}

Nanostructured Si solar cell with all-back-contact design. We achieved high efficiency from ultra-thin, nanostructured Si solar cells by designing an emitter layer at the back of the device rather than the front, which is a so-called all-back-contact design. As shown in Fig. 1a,b, the back side of our solar cell had an interdigitated structure of highly doped $\mathrm{p}^{+}$and $\mathrm{n}^{+}$regions. Its front side consisted of nanocones, which makes this ultra-thin device completely black. Remarkably, its EQE was $>80 \%$ in the spectrum of $400-800 \mathrm{~nm}$ wavelengths (Fig. 1c), which is superior to the EQE of any other nanostructured solar cells reported so far; in particular, its EQE at $400 \mathrm{~nm}$ wavelength was $80 \%$, which was at least 15\% higher than that of other Si nanostructured solar cells ${ }^{26}$ and $200 \%$ higher than that of III-V nanowire solar cells ${ }^{5}$. The significant light absorption, realized by the nanocones at the a

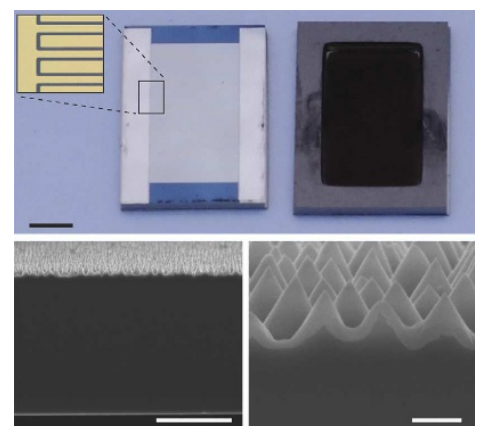

C

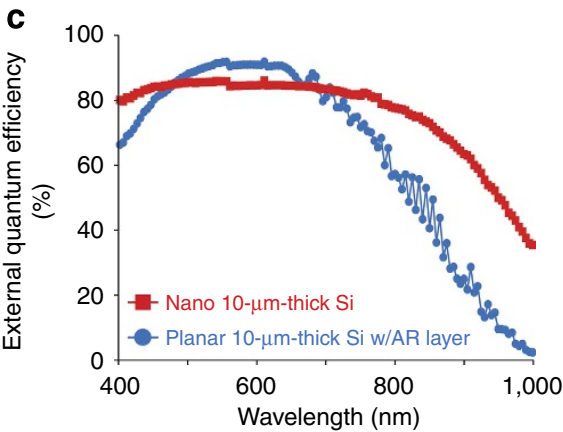

b

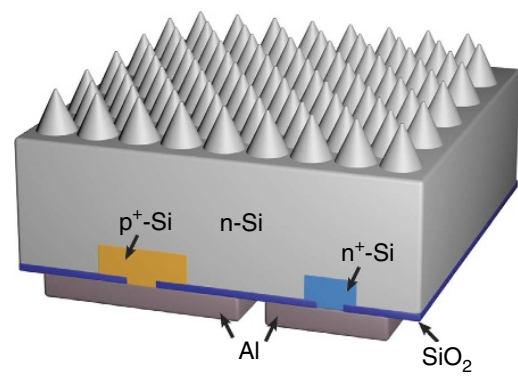

d

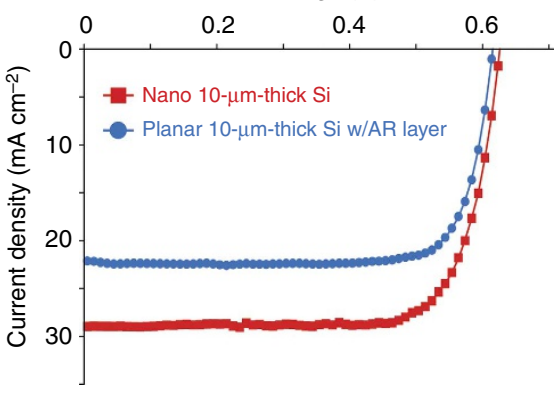

Figure 1 | Ultra-thin Si nanocone solar cell. (a) Optical image of the back (top, left) and front (top, right) side of the 10- $\mu$ m-thick Si solar cell. Inset shows the optical microscope image of the interdigitated metal electrodes. SEM images of cross-sectional view of the device (bottom, left) and cross-sectional view of the nanocones (bottom, right). The thin layer at the top of the nanocones is an 80 -nm-thick $\mathrm{SiO}_{2}$ layer. Scale bars are $2 \mathrm{~mm}$ (top), $5 \mu \mathrm{m}$ (bottom, left) and $400 \mathrm{~nm}$ (bottom, right). (b) Schematic illustration of the device. (c) EQE data of the device and a planar control. (d) J-V characteristics of two devices in $\mathbf{c}$. 
front, and the minimal loss of charge carriers, realized by the allback-contact design at the back, resulted in a short-circuit current density $\left(J_{\mathrm{SC}}\right)$ of $29.0 \mathrm{~mA} \mathrm{~cm}^{-2}$, which is $30.7 \%$ higher than the $J_{\mathrm{SC}}$ of a planar device coated with an anti-reflection layer $\left(\mathrm{Si}_{3} \mathrm{~N}_{4}\right.$, $80 \mathrm{~nm})$. The current density-voltage $(J-V)$ characteristics of the devices were measured under air mass 1.5 illumination, and they are presented in Fig. 1d and summarized in Table 1.

The all-back-contact design has been used to improve the power conversion efficiency in thick $\mathrm{Si}$ solar cells ${ }^{30,31}$, but we found that its benefits become more significant in nanostructured thin solar cells: microstructured thick Si solar cells showed $>85 \%$ $\mathrm{EQE}$ over the wavelengths of visible light, whether they had front-back-contact design ${ }^{32}$ or all-back-contact design ${ }^{33}$. The highest power conversion efficiency of thick Si solar cells in the world was achieved with the front-back-contact design ${ }^{34}$. In nanostructured thin $\mathrm{Si}$ solar cells, however, the front-backcontact design is not effective to collect charge carriers compared with the all-back-contact design: the deeper junction depth, heavy doping at the front surface and increased surface area in a nanostructured thin solar cell lead to a severe loss of the charge carriers generated near the front (Fig. 2a). Considering the fact that $>95 \%$ of light with $300-500 \mathrm{~nm}$ wavelengths is absorbed within $2 \mu \mathrm{m}$ of the nanostructured $\mathrm{Si}$ surface ${ }^{21}$, this loss can be significant. We confirmed the benefits of the all-back-contact design in nanostructured thin solar cells using simulation. We used a TCAD (technology-computer-aided design) simulation tool, Sentaurus: the optical properties were computed using the finite-difference time-domain method and they were integrated with the device simulation. Figure $2 \mathrm{~b}$ shows the calculated EQEs of four different $10-\mu \mathrm{m}$-thick devices. The simulation shows that the all-back-contact devices should have superior EQEs in the range of short wavelengths: with the surface recombination velocity $(S)$ of $100 \mathrm{~cm} \mathrm{~s}^{-1}$, the all-back-contact device had $94 \%$ $\mathrm{EQE}$ at $400 \mathrm{~nm}$ wavelength, whereas the front-back-contact

\begin{tabular}{|c|c|c|c|c|}
\hline & $J_{\mathrm{SC}}\left(\mathrm{mA} \mathrm{cm}{ }^{-2}\right)$ & $V_{\text {oc }}(V)$ & FF (\%) & PCE (\%) \\
\hline Nano $10-\mu \mathrm{m}$-thick Si & 29.0 & 0.623 & 76.0 & 13.7 \\
\hline $\begin{array}{l}\text { Planar } 10-\mu \mathrm{m} \text {-thick Si } \\
\text { w/AR layer }\end{array}$ & 22.2 & 0.615 & 80.2 & 10.9 \\
\hline
\end{tabular}

$F F$, fill factor; PCE, power conversion efficiency. device had only $28 \% \mathrm{EQE}$. The low EQE of the latter can be improved by decreasing the doping concentration at the front, but it can result in the higher series resistance and the lower efficiency. On the other hand, both devices showed similar EQEs over the spectrum of long wavelengths because light with those wavelengths is absorbed throughout the device, where the doping concentration is much lower $\left(3 \times 10^{15} \mathrm{~cm}^{-3}\right)$ than in the front $\left(4 \times 10^{20} \mathrm{~cm}^{-3}\right)$.

The simulation in Fig. $2 \mathrm{~b}$ shows the importance of the surface passivation in the all-back-contact design. As the surface recombination velocity $(S)$ increased from 100 to $1,000 \mathrm{~cm} \mathrm{~s}^{-1}$, the EQE of the all-back-contact devices decreased by $\sim 10 \%$. This study indicates that the high $\mathrm{EQE}$ of our device can be increased even further by improving the passivation on its front surface.

Advantages of nanocones. Another reason why our nanocone solar cell demonstrates superior EQE is the minimal increase of surface area. As mentioned before, the increased surface area in a nanostructured solar cell can lead to a severe decrease of efficiency. Nanostructures for thin Si solar cells should be designed to minimize the increase in surface area while enhancing the light absorption. Our nanocone structure with a height of about $400 \mathrm{~nm}$ and a diameter of $450 \mathrm{~nm}$ (Fig. 1b) satisfied both requirements. The total surface area of our nanocone structure is lower than that of other nanostructured Si solar cells: it is only $67 \%$ larger than that of a planar structure, whereas the surface area of nanopores, as mentioned above, is $>800 \% \operatorname{larger}^{26}$, and that of nanowires with $4 \mu \mathrm{m}$ height and $400 \mathrm{~nm}$ diameter is $2,000 \%$ larger $^{18}$. With the smallest surface area, our nanocone structure increased the light absorption significantly: the absorption of short-wavelength light $(400 \mathrm{~nm})$ was $96.1 \%$, which was $28 \%$ higher than that of the planar device coated with a 80 -nm-thick $\mathrm{Si}_{3} \mathrm{~N}_{4}$ anti-reflection layer, and the absorption of long-wavelength light $(900 \mathrm{~nm})$ was $83.8 \%$, which was $198 \%$ higher (Fig. 3). The remarkable enhancement of light absorption in our device was achieved by the optimal balance of antireflection and light-scattering effects from the nanocones: we previously found that the nanocone structure with an aspect ratio (height/diameter) close to 1 is the optimal design for the light absorption in thin Si (ref. 22), and our nanocone had an aspect ratio of 0.9 . The light absorption of our $10-\mu \mathrm{m}$-thick nanocone solar cell was comparable to that of $500-\mu \mathrm{m}$-thick planar $\mathrm{Si}$ coated with the anti-reflection layer $\left(80\right.$-nm-thick $\left.\mathrm{Si}_{3} \mathrm{~N}_{4}\right)$. It should be noted that there could be some parasitic light absorption at the metal contacts. Recently, the parasitic light absorption at the back contacts becomes increasingly important

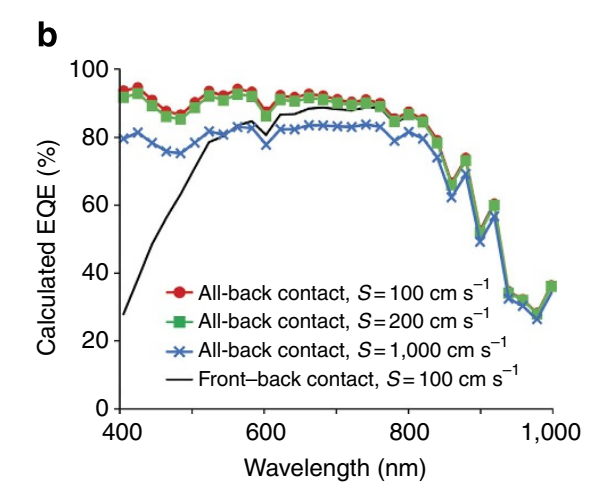

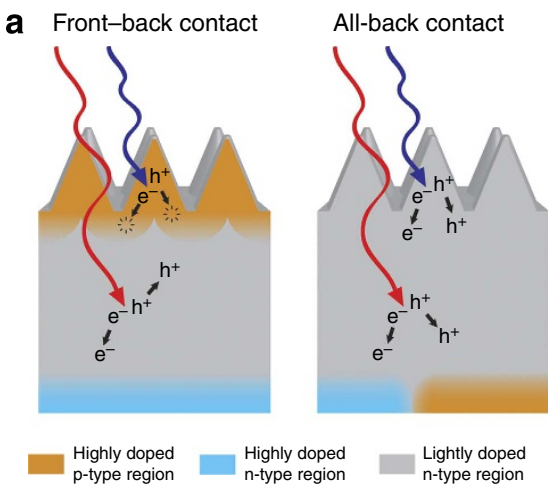

Figure 2 | Comparison of front-back-contact and all-back-contact designs. (a) Schematics of two different contact designs for thin Si solar cells. (b) Calculated EQE data of four different 10 - $\mu$ m-thick devices with the front-back-contact design and with the all-back-contact design. 
because a thinner absorber layer allows more light to reach at the back of a solar cell ${ }^{35-37}$. The simulation in Fig. 4 indicates that the absorption of long-wavelength light $(900 \mathrm{~nm})$ at the back contacts, aluminium (Al), could increase up to $10 \%$ and $25 \%$ with and without $\mathrm{SiO}_{2}$ layer between $\mathrm{Si}$ and $\mathrm{Al}$, respectively. The lower parasitic absorption with the $\mathrm{SiO}_{2}$ layer can be due to the higher internal reflection from the back ${ }^{37}$. Because $60 \%$ of the back surface of our solar cell was covered with an 80 -nm-thick $\mathrm{SiO}_{2}$ layer (details in the Methods section), the parasitic absorption of long-wavelength light could be $>10 \%$. A further optimization of the back contact design will be able to increase the Si light absorption and enhance the $J_{S C}$. From the light absorption measurement shown in Fig. 3, we realized that our ultra-thin nanocone $\mathrm{Si}$ solar cell could achieve $>34 \mathrm{~mA} \mathrm{~cm}^{-2}$ $J_{\mathrm{SC}}$. Considering the measured $J_{\mathrm{SC}}\left(29 \mathrm{~mA} \mathrm{~cm}^{-2}\right)$ from our device, $\sim 5 \mathrm{~mA} \mathrm{~cm}^{-2}$ was lost because of the recombination and the parasitic absorption.

Over the wavelength range of $500-700 \mathrm{~nm}$, the nanocone device and the planar device absorbed similar amount of light, because the anti-reflection layer in the planar device improved the light absorption. The planar device had a smaller surface area than the nanocone device, which allowed the planar device to

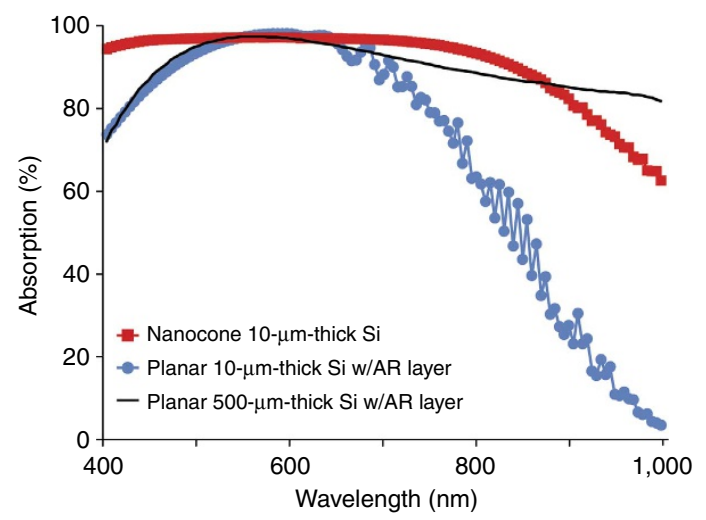

Figure 3 | Light absorption data of three devices. The anti-reflection (AR) layer was $\mathrm{Si}_{3} \mathrm{~N}_{4}$ with a thickness of $80 \mathrm{~nm}$.

a
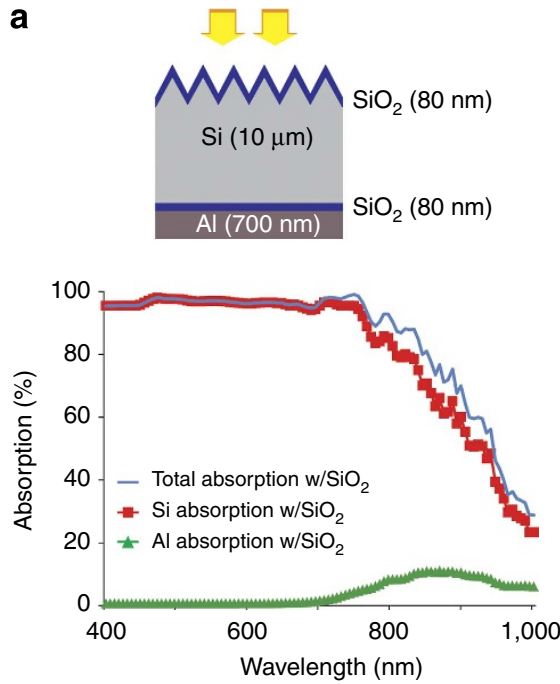

have lower surface recombination and higher EQEs than the nanocone device over 500-700 $\mathrm{nm}$ wavelengths (Fig. 1c).

Effect of pitch between two contacts on thin Si solar cells. We further exploited the advantages of the all-back-contact design in our nanostructured solar cell by optimizing the pitch between the two contacts. For thick Si solar cells with the all-back-contact design, the pitch is normally $>400 \mu \mathrm{m}$, which allows less complicated fabrication processes such as screen-printing of metal contacts $^{38-40}$. Previous studies have found that the fill factor (FF) was the only parameter that depended on the pitch in thick $\mathrm{Si}$ solar cells ${ }^{41,42}$. We, however, found that the $J_{\mathrm{SC}}$ as well as the FF was closely dependent on the pitch in thin Si solar cells. Figure $5 \mathrm{a}$ shows the $J-V$ characteristics of $10-\mu \mathrm{m}$-thick $\mathrm{Si}$ solar cells fabricated with the same nanostructures but different pitches between the back contacts. The FF and the $J_{\mathrm{SC}}$ were increased by $23.5 \%$ and $5.4 \%$, respectively, as the pitch decreased from $400-50 \mu \mathrm{m}$. The main factor for the increased FF is the decreased series resistance, $R_{\mathrm{S}}$ (Table 2 ). We used device simulation to understand these experimental results. In the simulation, we assumed no reflection from the device in order to imitate the case where there were nanocones. Figure $5 \mathrm{~b}-\mathrm{e}$ shows the simulation structure and data of $10-\mu \mathrm{m}$-thick Si solar cells as a function of the pitch. Decreases in FF and $J_{\mathrm{SC}}$ with the larger pitch (Fig. $5 \mathrm{c}, \mathrm{d}$ ) can be explained by the path length over which charge carriers must diffuse to be collected in a thin device: the path length increases with the larger pitch, which results in higher series resistance and higher recombination of charge carriers, as illustrated in Fig. 5b. Because the minority carrier lifetime was $1 \mathrm{~ms}$ in this simulation, the recombination loss was mainly due to the surface recombination, and we confirmed that the decrease in $J_{\mathrm{SC}}$ became significant as the effective surface recombination velocity $\left(S_{\mathrm{Eff}}\right)$ increased (Fig. $\left.5 \mathrm{~d}\right) . S_{\mathrm{Eff}}$ is the local surface recombination velocity $(S)$ multiplied by the increased surface area: a planar device has $S_{\mathrm{Eff}}$, equivalent to $S$, and a nanostructured device with a $N$ times larger surface area (compared with the planar one) has $S_{\mathrm{Eff}}, N$ times larger than $S^{26}$. Interestingly, the decrease in $J_{\mathrm{SC}}$ in the experiment was much smaller than that in the simulation. It might be due to the geometric difference between the experiment (nanocone structure) and the simulation (planar structure), but the quantitative analysis on the loss

b
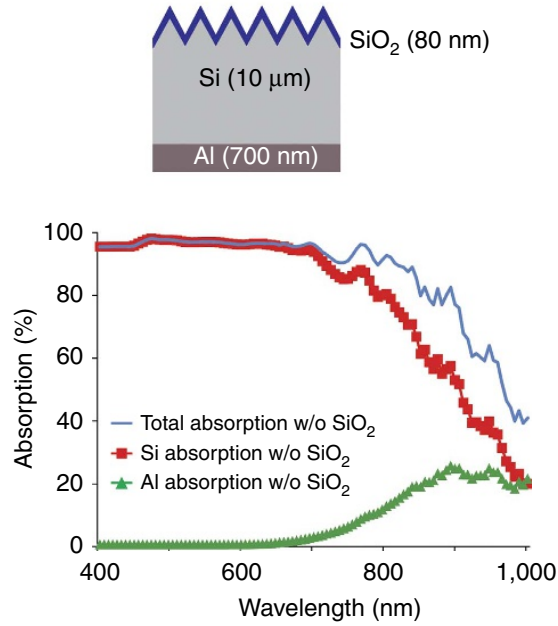

Figure 4 | Simulation schematics and data of light absorption in 10- $\mu$ m-thick Si nanocone solar cells. (a) With a $\mathrm{SiO}_{2}$ layer between $\mathrm{Si}$ and $\mathrm{Al}$ contacts. (b) Without a $\mathrm{SiO}_{2}$ layer between $\mathrm{Si}$ and $\mathrm{Al}$ contacts. In order to minimize the interference pattern, the moving-average method (four-point) was applied in the data. 
a

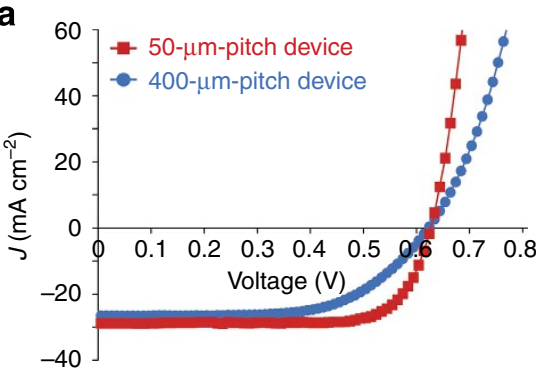

C
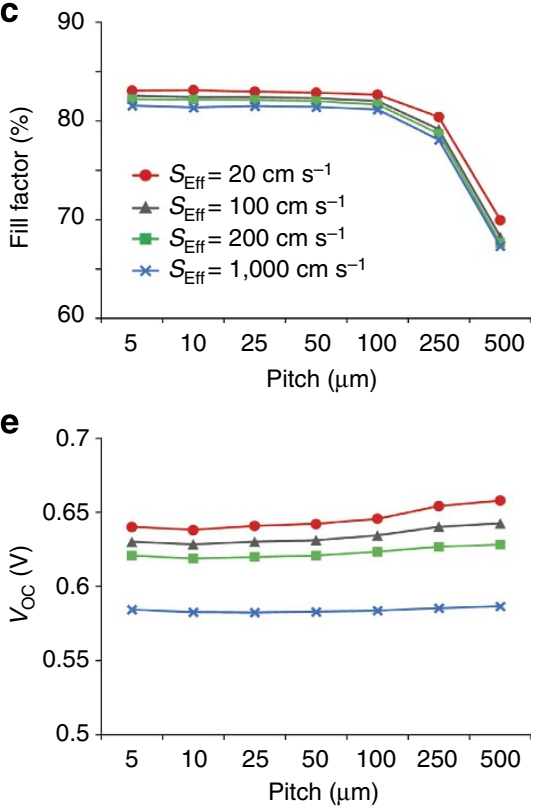

b

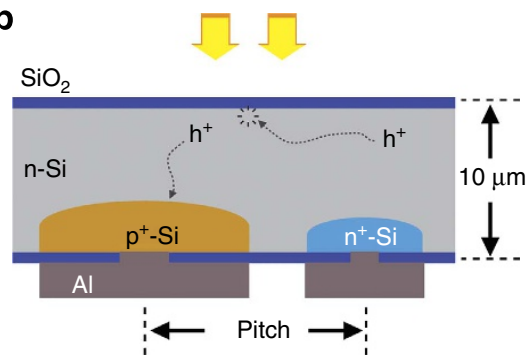

d

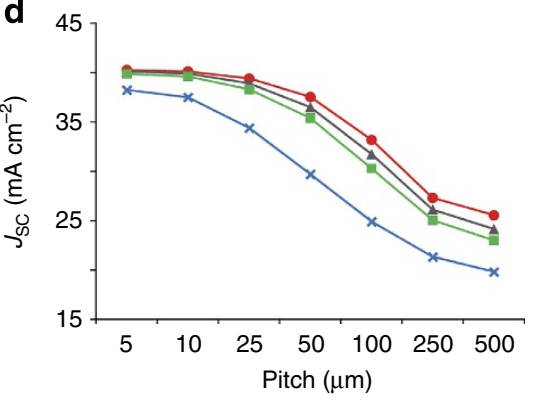

f

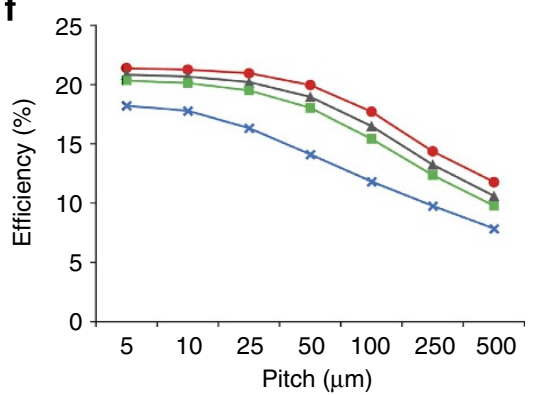

Figure 5 | Photovoltaic properties of 10- $\mu$ m-thick Si solar cells. (a) Experimental results of $10-\mu m$-thick Si solar cells with the same nanostructures but different pitches of the back contacts: one with 50- $\mu$ m-pitch and the other with 400- $\mu$ m-pitch. They are the average value from eight devices in both cases. (b) Schematic illustration of the simulated device structure. (c-f) Simulation data of FF (c), $J_{\mathrm{SC}}$ (d), $V_{\mathrm{OC}}$ (e) and efficiency (f) as functions of pitch and effective surface recombination velocity $\left(S_{\mathrm{Eff}}\right)$.

Table 2 | Photovoltaic properties of ultra-thin Si solar cells in Fig. 5.

\begin{tabular}{|c|c|c|c|c|c|c|c|}
\hline & $J_{\mathrm{SC}}\left(\mathrm{mA} \mathrm{cm}{ }^{-2}\right)$ & $V_{\text {oc }}(\mathrm{V})$ & FF (\%) & PCE (\%) & $R_{\mathrm{SH}}\left(\Omega . \mathrm{cm}^{2}\right)$ & $R_{\mathrm{S}}\left(\Omega . \mathrm{cm}^{2}\right)$ & $\sigma$ (s.d.) of $J_{\mathrm{SC}}$ \\
\hline Avg. $10-\mu \mathrm{m}$-thick Si w/50 $\mu \mathrm{m}$-pitch & 28.2 & 0.622 & 76.5 & 13.4 & $5.69 k$ & 0.33 & 0.91 \\
\hline Difference (\%) & +5.41 & +0.810 & +23.5 & +31.3 & -17.0 & -61.9 & \\
\hline
\end{tabular}

mechanism of charge carriers in nanostructured and planar devices needs to be investigated further. On the other hand, the open-circuit voltage $\left(V_{\mathrm{OC}}\right)$ increased slightly as the pitch increased, and it might be due to the decreased junction area: When the pitch was $50 \mu \mathrm{m}$, the $\mathrm{n}^{+} / \mathrm{p}^{+}$regions were 30 and $46 \mu \mathrm{m}$, respectively. When the pitch was $5 \mu \mathrm{m}$, the $\mathrm{n}^{+} / \mathrm{p}^{+}$ regions were 3 and $4.6 \mu \mathrm{m}$, respectively. The pn junction area in the larger pitch device was smaller than that in the smaller pitch device, which could decrease the saturation current density and increase the $V_{\mathrm{OC}}$ in the larger pitch device. However, as the $S_{\mathrm{Eff}}$ increased, the effect of the junction area decreased, and the $V_{\mathrm{OC}}$ became less sensitive to the pitch. These combined effects of FF, $J_{\mathrm{SC}}$ and $V_{\mathrm{OC}}$ indicate that nanostructured thin Si solar cells with the all-back-contact design should be designed to have both smaller pitch and less surface area. We also confirmed that the design principle, smaller pitch and less surface area, should be applied to thick solar cells, as well as thin ones, with the all-backcontact design (Supplementary Fig. S1).

Effect of minority carrier lifetime on thin $\mathrm{Si}$ solar cells. Our ultra-thin Si nanocone solar cell can be fabricated with inexpensive, less-pure material. Conventional Si solar cells with the all-back-contact design need a very long lifetime of minority carriers (more than $1 \mathrm{~ms}$ ), because their thickness is normally $>150 \mu \mathrm{m}$ and the charge carriers should diffuse to the back without recombination. This requires high-purity material and increases the solar cell cost. Our device is $>15$ times thinner than the conventional one, thus the charge carriers in our device need to diffuse 15 times shorter. It implies that the ultra-thin Si solar cell with the all-back-contact design can be fabricated with a lesspure material. We confirmed this benefit of the ultra-thin device 
a

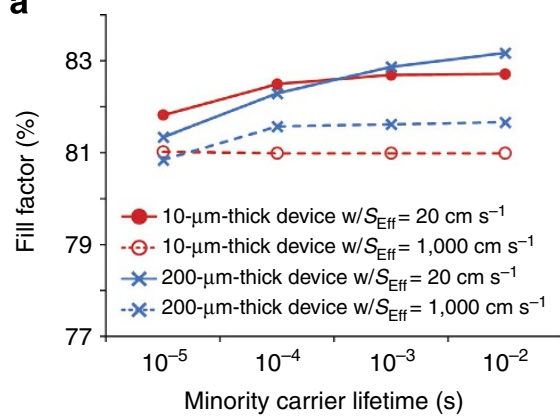

C

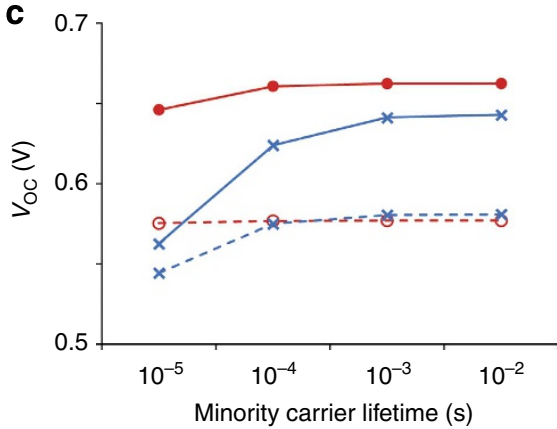

b

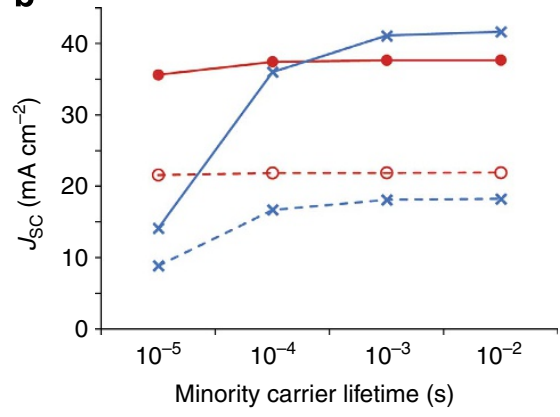

d

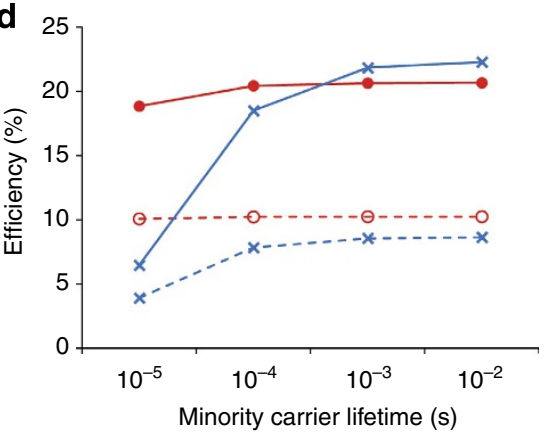

Figure 6 | Photovoltaic properties of thin and thick Si solar cells. Simulation data of FF (a), $J_{\mathrm{SC}}(\mathbf{b}), V_{\mathrm{OC}}(\mathbf{c})$ and efficiency (d) as functions of minority carrier lifetime and effective surface recombination velocity $\left(S_{\text {Eff }}\right)$.

using device simulation. The simulation structure was the same as shown in Fig. 5b, and the pitch was set to $50 \mu \mathrm{m}$. Figure 6 compares the photovoltaic properties of 10 - and $200-\mu \mathrm{m}$-thick solar cells with different minority carrier lifetimes and surface recombination velocities. With the surface recombination velocity of $20 \mathrm{~cm} \mathrm{~s}^{-1}$, the $10-\mu \mathrm{m}$-thick device showed $>20 \%$ efficiency as the lifetime decreased by two orders of magnitude, from $10 \mathrm{~ms}$ to $100 \mu \mathrm{s}$. When the lifetime went down to $10 \mu \mathrm{s}$, the efficiency was still close to $20 \%$. In contrast, the efficiency of the $200-\mu \mathrm{m}$-thick device was changed significantly, from $21.8 \%$ to $6.5 \%$, as the lifetime decreased from $1 \mathrm{~ms}$ to $10 \mu \mathrm{s}$. Interestingly, the $V_{\mathrm{OC}}$ of the $10-\mu \mathrm{m}$-thick solar cell was higher than that of the $200-\mu \mathrm{m}$ thick solar cell when the $S_{\text {Eff }}$ was $20 \mathrm{~cm} \mathrm{~s}^{-1}$. Because of the 20 times thinner substrate, the charge carrier concentration in the $10-\mu \mathrm{m}$-thick device was much higher than that of the $200-\mu \mathrm{m}$ thick device, which led to higher $V_{\mathrm{OC}}{ }^{41,43}$. This simulation study shows that well-passivated thin Si solar cells made of inexpensive material can achieve the high efficiency comparable to that of conventional thick Si solar cells made of expensive material.

\section{Discussion}

We achieved $13.7 \%$ power conversion efficiency from a sub-10$\mu$ m-thick Si solar cell. Our ultra-thin device demonstrated more than $80 \%$ EQE at short-wavelength light, which was superior to that of any other nanostructured Si solar cell. This improvement was achieved by overcoming critical problems in nanostructured solar cells. Our device had two main advantages: the all-backcontact design and the nanocones. Its all-back-contact design prevented Auger recombination loss near the front, and its nanocone structure minimized the increase in surface area while enhancing the light absorption significantly. From the device simulation, we inferred that the effective surface recombination velocity of our ultra-thin Si solar cell was $\sim 1000 \mathrm{~cm} \mathrm{~s}^{-1}$ and its efficiency could be higher than $20 \%$ with good surface passivation. The design principles that we outlined for highly efficient, ultra-thin Si solar cells show the potential of the nanostructured $\mathrm{Si}$ solar cell to be a cost-effective solution for next-generation photovoltaic devices.

\section{Methods}

Si solar cell fabrication. We used a silicon-on-insulator (SOI) wafer for the solar cell fabrication. Its device layer was Czochralski (CZ) Si, 10- $\mu \mathrm{m}$ thick and N-type with a resistivity of $1-5 \Omega . c m$. First, as a doping mask, a $300-\mathrm{nm}$-thick $\mathrm{SiO}_{2}$ layer was grown thermally on the SOI wafer. At the surface of the device layer, interdigitated patterns for $\mathrm{n}^{+} / \mathrm{p}^{+}$regions were fabricated with photolithography. The widths of the $\mathrm{n}^{+} / \mathrm{p}^{+}$regions were $30 / 46 \mu \mathrm{m}$, respectively, and the centre-to-centre distance (pitch) between the $\mathrm{n}^{+}$and $\mathrm{p}^{+}$regions was $50 \mu \mathrm{m}$. After the patterning, gas-phase doping processes $\left(\mathrm{n}^{+}\right.$with $\mathrm{POCl}_{3}$ and $\mathrm{p}^{+}$with $\left.\mathrm{BBr}_{3}\right)$ were conducted using the atmospheric furnace, tylan. The sheet resistance for the $\mathrm{n}^{+}$region was 85-90 $\Omega$ per square, and that for the $\mathrm{p}^{+}$region was $72-75 \Omega$ per square. After the doping processes, the window patterns were defined at the back side (handle layer) of the SOI wafer: (1) the front side (device layer) was coated with $3-\mu \mathrm{m}$-thick photoresist for protection, (2) the SOI wafer was flip-over and (3) the back side of the SOI wafer was aligned and exposed in the ultra-violet light $(365 \mathrm{~nm})$. The window patterns at the back side of the wafer were etched by deep reactive-ion etching (RIE) method, which defined the solar cell area. The exposed buried oxide part was removed by wet etching, and an array of Si nanocones was fabricated by dry etching. In order to remove the surface defects formed during the nanocone fabrication process, an 80 -nm-thick $\mathrm{SiO}_{2}$ layer was grown thermally over the whole structure. The patterns for metal contacts were fabricated with photolithography at the $\mathrm{n}^{+} / \mathrm{p}^{+}$regions at the device layer: the widths of the contacts to the $\mathrm{n}^{+} / \mathrm{p}^{+}$ regions were $15 / 25 \mu \mathrm{m}$, respectively. For the contacts, $\mathrm{Al}$ (a thickness of $700 \mathrm{~nm}$ ) was deposited by electron-beam evaporation.

Si nanocone fabrication. We used colloidal lithography to make Si nanocones: (1) a monolayer of silica nanoparticles (a diameter of $500 \mathrm{~nm}$ ) was formed on a $\mathrm{Si}$ substrate with the Langmuir-Blodgett method. The nanoparticles were synthesized with the modified Stöber process using the hydrolyses of tetraethyl orthosilicate in ethanol containing ammonia ${ }^{44}$. (2) The nanoparticles were etched by RIE to have a diameter of $200 \mathrm{~nm}$. A gas mixture of oxygen $\left(\mathrm{O}_{2}\right)$ and trifluoromethane $\left(\mathrm{CHF}_{3}\right)$ was flowed with a rate of 6 and $85 \mathrm{sccm}$, respectively. These etched nanoparticles acted as a mask for Si etching. (3) The silica nanoparticles and the Si substrate were etched by RIE with a gas mixture of chlorine $\left(\mathrm{Cl}_{2}\right)$ and hydrogen bromide $(\mathrm{HBr})$. Because of the selectivity, Si nanocones were formed in this step.

Device simulation. We used a TCAD simulation tool, Sentaurus, supported by Synopsys, Inc. In order to simulate the solar cell properties, we specified the following: Substrate was n-type, doped with phosphorous (a concentration of $\left.3 \times 10^{15} \mathrm{~cm}^{-3}\right) . \mathrm{N}^{+}$region was doped with phosphorous (concentration of 
$1 \times 10^{20} \mathrm{~cm}^{-3}$, diffusion depth of $\left.100 \mathrm{~nm}\right) . \mathrm{P}^{+}$region was doped with boron (concentration of $4 \times 10^{20} \mathrm{~cm}^{-3}$, diffusion depth of $300 \mathrm{~nm}$ ).

The device geometry in the simulation was identical to the geometry of the real solar cell $\left(30-\mu \mathrm{m}\right.$-wide $\mathrm{n}^{+}, 46-\mu \mathrm{m}$-wide $\mathrm{p}^{+}$and $50-\mu \mathrm{m}$-wide pitch). For the simulation of the photovoltaic properties as a function of pitch, the geometry was changed linearly: when the pitch increased to $100 \mu \mathrm{m}$, the widths of the $\mathrm{n}^{+} / \mathrm{p}^{+}$ regions increased to $60 / 92 \mu \mathrm{m}$, respectively.

Light absorption measurement. The light transmission and reflection were measured with an integrating sphere (Newport, 3.3" diameter). A tungsten lamp coupled to a monochromator was used as a light source. The sample was mounted at the centre of the integrating sphere, and it was rotated with an angle of $5^{\circ}$. There were only two holes in the integrating sphere: one for the light source and the other for the detector. After the reference signal was measured without any sample in the integrating sphere, our solar cell was mounted at the centre of the sphere. The collected light in the detector was a sum of the reflected and transmitted light from the sample. We calculated the absorption by the equation as follows:

$$
1-(\text { reflection }+ \text { transmission })=\text { absorption }
$$

\section{References}

1. Gur, I., Fromer, N. A., Geier, M. L. \& Alivisatos, A. P. Air-stable all-inorganic nanocrystal solar cells processed from solution. Science 310, 462-465 (2005).

2. O’Regan, B. \& Grätzel, M. A low-cost, high-efficiency solar cell based on dye-sensitized colloidal TiO2 films. Nature 353, 737-740 (1991).

3. Law, M., Greene, L. E., Johnson, J. C., Saykally, R. \& Yang, P. Nanowire dye-sensitized solar cells. Nat. Mater. 4, 455-459 (2005).

4. Tang, J. et al. Colloidal-quantum-dot photovoltaics using atomic-ligand passivation. Nat. Mater. 10, 765-771 (2011).

5. Wallentin, J. et al. InP nanowire array solar cells achieving $13.8 \%$ efficiency by exceeding the ray optics limit. Science 339, 1057-1060 (2013).

6. Tang, J., Huo, Z., Brittman, S., Gao, H. \& Yang, P. Solution-processed coreshell nanowires for efficient photovoltaic cells. Nat. Nanotech. 6, 568-572 (2011).

7. Zhu, J., Hsu, C.-M., Yu, Z., Fan, S. \& Cui, Y. Nanodome solar cells with efficient light management and self-cleaning. Nano Lett. 10, 1979-1984 (2010).

8. Kelzenberg, M. D. et al. Enhanced absorption and carrier collection in Si wire arrays for photovoltaic applications. Nat. Mater. 9, 239-244 (2010).

9. Garnett, E. C., Brongersma, M. L., Cui, Y. \& McGehee, M. D. Nanowire solar cells. Annu. Rev. Mater. Res. 41, 269-295 (2011).

10. Yoon, J. et al. Ultrathin silicon solar microcells for semitransparent, mechanically flexible and microconcentrator module designs. Nat. Mater. 7, 907-915 (2008)

11. Fan, Z. et al. Three-dimensional nanopillar-array photovoltaics on low-cost and flexible substrates. Nat. Mater. 8, 648-653 (2009).

12. Tian, B. et al. Coaxial silicon nanowires as solar cells and nanoelectronic power sources. Nature 449, 885-889 (2007).

13. Goodrich, A. C., Powell, D. M., James, T. L., Woodhouse, M. \& Buonassisi, T. Assessing the drivers of regional trends in solar photovoltaic manufacturing. Energy Environ. Sci. 6, 2811-2821 (2013).

14. U.S. Department of Energy. SunShot Vision Study. 69-96 (2012).

15. Mavrokefalos, A., Han, S. E., Yerci, S., Branham, M. S. \& Chen, G. Efficient light trapping in inverted nanopyramid thin crystalline silicon membranes for solar cell applications. Nano Lett. 12, 2792-2796 (2012).

16. Powell, D. M. et al. Crystalline silicon photovoltaics: a cost analysis framework for determining technology pathways to reach baseload electricity costs. Energy Environ. Sci. 5, 5874-5883 (2012).

17. Kim, D. R., Lee, C. H., Rao, P. M., Cho, I. S. \& Zheng, X. Hybrid Si microwire and planar solar cells: passivation and characterization. Nano Lett. 11, 2704-2708 (2011).

18. Garnett, E. \& Yang, P. Light trapping in silicon nanowire solar cells. Nano Lett. 10, 1082-1087 (2010)

19. Kempa, T. J. et al. Coaxial multishell nanowires with high-quality electronic interfaces and tunable optical cavities for ultrathin photovoltaics. Proc. Natl Acad. Sci. USA 109, 1407-1412 (2012).

20. Zhu, J. et al. Optical absorption enhancement in amorphous silicon nanowire and nanocone arrays. Nano. Lett. 9, 279-282 (2009).

21. Wang, K. X., Yu, Z., Liu, V., Cui, Y. \& Fan, S. Absorption enhancement in ultrathin crystalline silicon solar cells with antireflection and light-trapping nanocone gratings. Nano Lett. 12, 1616-1619 (2012).

22. Jeong, S. et al. Hybrid Si nanocone-polymer solar cells. Nano. Lett. 12, 2971-2976 (2012)

23. Leung, S.-F. et al. Efficient photon capturing with ordered three-dimensional nanowell arrays. Nano. Lett. 12, 3682-3689 (2012).

24. Han, S. E. \& Chen, G. Optical absorption enhancement in silicon nanohole arrays for solar photovoltaics. Nano. Lett. 10, 1012-1015 (2010).

25. Peng, K.-Q., Wang, X., Li, L., Wu, X.-L. \& Lee, S.-T. High-performance silicon nanohole solar cells. J. Am. Chem. Soc. 132, 6872-6873 (2010).
26. Oh, J., Yuan, H.-C. \& Branz, H. M. An 18.2\%-efficient black-silicon solar cell achieved through control of carrier recombination in nanostructures. Nat. Nanotech. 7, 743-748 (2012).

27. Lu, Y. \& Lal, A. High-efficiency ordered silicon nano-conical-frustum array solar cells by self-powered parallel electron lithography. Nano. Lett. 10, 4651-4656 (2010).

28. Ok, Y. et al. Abnormal dopant distribution in $\mathrm{POCl}_{3}$-diffused $\mathrm{N}^{+}$emitter of textured silicon solar cells. IEEE Electron Device Lett. 32, 351-353 (2011).

29. King, R. R., Sinton, R. A. \& Swanson, R. M. Studies of diffused phosphorus emitters: saturation current, surface recombination velocity, and quantum efficiency. IEEE Trans. Electron Dev. 37, 365-371 (1990).

30. Sinton, R. A. \& Swanson, R. M. Simplified backside-contact solar cells. IEEE Trans. Electron Dev. 37, 348-352 (1990).

31. Zin, N. et al. Progress in the development of all-back-contacted silicon solar cells. Energy Procedia 25, 1-9 (2012).

32. Benick, J. et al. High-efficiency n-type silicon solar cells with front side boron emitter. in Proc. 24th EU PVSEC 863-870 (Hamburg, Germany, 2009).

33. Mulligan, W. P. et al. Manufacture of solar cells with $21 \%$ efficiency. in Proc. 19th EU PVSEC 387-390 (Paris, France, 2004).

34. Green, M. A., Emery, K., Hishikawa, Y., Warta, W. \& Dunlop, E. D. Solar cell efficiency tables (version 41). Prog. Photovolt Res. Appl. 21, 1-11 (2013).

35. Holman, Z. C. et al. Infrared light management in high-efficiency silicon heterojunction and rear-passivated solar cells. J. Appl. Phys. 113, 013107 (2013).

36. Sai, H., Jia, H. \& Kondo, M. Impact of front and rear texture of thin-film microcrystalline silicon solar cells on their light trapping properties. J. Appl. Phys. 108, 044505 (2010).

37. Holman, Z. C. et al. Parasitic absorption in the rear reflector of a silicon solar cell: simulation and measurement of the sub-bandgap reflectance for common dielectric/metal reflectors. Sol. Energy Mater. Sol. Cells 120, 426-430 (2014).

38. Gong, C. et al. High efficient n-type back-junction back-contact silicon solar cells with screen-printed Al-alloyed emitter and effective emitter passivation study. Prog. Photovolt. Res. Appl. 19, 781-786 (2011).

39. Woehl, R., Krause, J., Granek, F. \& Biro, D. 19.7\% efficient all-screen-printed back-contact back-junction silicon solar cell with aluminum-alloyed emitter. IEEE Electron Device Lett. 32, 345-347 (2011).

40. Petermann, J. H. et al. $19 \%$-efficient and $43 \mu \mathrm{m}$-thick crystalline Si solar cell from layer transfer using porous silicon. Prog. Photovolt. Res. Appl. 20, 1-5 (2012).

41. Swanson, R. M. Point-contact solar cells: modeling and experiment. Sol. Cells 17, 85-118 (1986).

42. Kim, D. et al. 2D-modeling and development of interdigitated back contact solar cells on low-cost substrates. IEEE 4th World Conf. Photovolt. Energy Convers. 1417-1420 (2006).

43. Tiedje, T., Yablonovitch, E., Cody, G. D. \& Brooks, B. G. Limiting efficiency of silicon solar cells. IEEE Trans. Electron Devices 31, 711-716 (1984).

44. Bogush, G. H., Tracy, M. A. \& Zukoski, IV C. F. Preparation of monodisperse silica particles: control of size and mass fraction. J. Non-Cryst. Solids 104, 95-106 (1988)

\section{Acknowledgements}

This work was based upon the work supported as part of the Bay Area Photovoltaic Consortium (BAPVC) at Stanford University funded by the U.S. Department of Energy Sunshot Initiative. S.J. acknowledges support from the Korea Foundation for Advanced Studies (KFAS) for graduate fellowship. S.J. thanks Dr Theodore I. Kamins, Dr Jung Ho Yu, Dr Junghyun Park and Shuang Wang for helpful discussions concerning the device fabrication and simulation.

\section{Author contributions}

S.J. and Y.C. conceived and developed the concept. S.J. conducted sample fabrication, measurement and electrical and optical simulation. Y.C. supervised the whole project. All the authors contributed to the analysis and discussion of the results and wrote the manuscript.

\section{Additional information}

Supplementary Information accompanies this paper at http://www.nature.com/ naturecommunications

Competing financial interests: The authors declare no competing financial interests

Reprints and permission information is available online at http://npg.nature.com/ reprintsandpermissions/

How to cite this article: Jeong, S. et al. All-back-contact ultra-thin silicon nanocone solar cells with $13.7 \%$ power conversion efficiency. Nat. Commun. 4:2950 doi: 10.1038/ncomms3950 (2013). 